\title{
Regulation of cell apoptosis and proliferation in pancreatic cancer through PI3K/Akt pathway via Polo-like kinase 1
}

\author{
YONGHUAN MAO ${ }^{1 *}$, LING XI $^{2 *}$, QUAN LI $^{1}$, ZELING CAI $^{1}$, YIMEI LAI $^{3}$, \\ XINHUA ZHANG ${ }^{4}$ and CHUNZHAO YU ${ }^{1}$ \\ ${ }^{1}$ Department of General Surgery, The Second Clinical Medical School of Nanjing Medical University; \\ Departments of ${ }^{2}$ Gerontology and ${ }^{3}$ Pathology, The First Clinical Medical School of Nanjing Medical University; \\ ${ }^{4}$ Department of Pediatric Medicine, Jiangsu Province Hospital, Nanjing, Jiangsu 210029, P.R. China
}

Received February 9, 2016; Accepted March 4, 2016

DOI: $10.3892 / o r .2016 .4820$

\begin{abstract}
Pancreatic cancer has a poor prognosis. It is reported that the PI3K/Akt pathway is activated in many cancers, and inhibition of the PI3K/Akt pathway can induce cell apoptosis in most cancers. Polo-like kinase 1 (Plk1) is also overexpressed in most malignancies, and it controls multiple aspects of mitosis and apoptosis. Previous studies identified that PI3K/ Akt-dependent phosphorylation of Plk1-Ser99 is required for metaphase-anaphase transition. In this study, we aimed to investigate the molecular mechanism of PI3K/Akt pathway regulating cell proliferation and apoptosis in pancreatic cancer cell lines (AsPC-1, BxPC-3, PANC-1). Immunohistochemistry (IHC) was used to assess Akt levels in human pancreatic tissues and pancreatic cancer tissues. MTT assay was used to detect cell proliferation. The mRNA was quantified by quantitative reverse transcription-PCR. Western blot analysis was used to detect the protein levels of p-Akt, Akt, Plk1, BAX, Bcl-2, XIAP, cleaved caspase-3 and caspase-3. Recombinant adenovirus vector containing Plk1-shRNA was constructed to inhibit Plk1 expression. Cell apoptosis was detected by flow cytometry and the apoptosis of tumor xenograft was assessed by TUNEL assay. The study showed that inhibition of PI3K/Akt pathway can induce cell apoptosis and reduce cell proliferation by downregulating Plk1 in vitro and in vivo. Additionally, Plk1 inhibition can lead to cancer cell apoptosis through inactivating XIAP, activating caspase-3, upregulating BAX and downregulating Bcl-2. Therefore, this study provided the molecular mechanism of PI3K/Akt pathway and Plk1 in
\end{abstract}

Correspondence to: Dr Chunzhao Yu, Department of General Surgery, The Second Clinical Medical Hospital of Nanjing Medical University, 121 Jiangjiayuan, Nanjing, Jiangsu 210029, P.R. China E-mail: slee1989@163.com

*Contributed equally

Key words: pancreatic cancer, PI3K/Akt pathway, Plk1, apoptosis, proliferation the pancreatic cancer cell proliferation and apoptosis, which may benefit for the therapy of pancreatic cancer.

\section{Introduction}

Pancreatic cancer has a poor prognosis with a 5-year survival of $<5 \%$ and the fourth most deadly cancer (1). The poor prognosis of pancreatic cancer is associated with its chemotherapy resistance and early metastasis $(2,3)$. Hence, the high mortality of pancreatic cancer indicates a requirement for early detection and novel therapies.

The PI3K/Akt pathway, a survival signaling pathway, is involved in the control of cell apoptosis and proliferation and $>50 \%$ human cancers are related to the deregulation of this pathway, including pancreatic cancer (4-7). Akt contributes to cell plasticity in pancreas as a regulator and its overexpression has been proved to be a common phenomenon in pancreatic cancer (8-11). Therefore, the PI3K/Akt pathway plays a crucial role in the development of pancreatic cancer.

Polo-like kinase 1 (Plk1), a serine/threonine kinase, plays an important role in cell cycle and apoptosis (12). Plk1 is overexpressed in various tumors and its overexpression is associated with poor prognosis $(12,13)$. Plk1 overexpression is a common and early event and contributes to gemcitabine resistance in pancreatic cancer $(14,15)$.

Apoptosis occurs in multicellular organisms as a programmed cell death and it can be activated through intrinsic pathway and extrinsic pathway (16). The intrinsic pathway involves the mitochondria (17). Activation of caspases is an important process for the intrinsic pathway and is controlled by anti- or pro-apoptotic proteins, such as XIAP, Bcl-2 and $\operatorname{BAX}(18,19)$.

In cell cycle, PI3K/Akt-dependent phosphorylation of Plk1-Ser99 is required for metaphase-anaphase transition and Plk1-dependent phosphorylation of IRS2-S556 inhibits mitotic exit through reducing Akt activity $(20,21)$. However, the mechanism of cell apoptosis induced by PI3K/Akt pathway and Plk1 still remains unclear.

In this study, we investigated the function of PI3K/Akt pathway on cell proliferation and apoptosis in pancreatic carcinoma in vitro and in vivo and the effect of Plk1 in this process. Our results could help to understand apoptosis-related 
pathway, such as caspase-related or Bcl-2 family-mediated pathway, and benefit the therapy of pancreatic cancer.

\section{Materials and methods}

Cell culture and antibodies. Human pancreatic cancer cell lines (AsPC-1, BxPC-3, PANC-1) were acquired from ATCC (Manassas, VA, USA) and maintained in RPMI-1640 medium (Gibco, Gaithersburg, MD, USA), supplemented with $100 \mathrm{U} / \mathrm{ml}$ penicillin, $100 \mathrm{U} / \mathrm{ml}$ streptomycin, and $10 \%$ fetal bovine serum (FBS) (Gibco) at $37^{\circ} \mathrm{C}$ in $5 \% \mathrm{CO}_{2}$. Antibodies against p-Akt, Akt, Plk1, XIAP, caspase-3, cleaved caspase-3 were purchased from Cell Signaling Technology (Beverly, MA, USA) for western blot analysis. Antibodies against Bcl-2, BAX were purchased from Abcam (Abcam, UK) for western blot analysis. Akt antibody for immunohistochemistry (IHC) was purchased from Abcam (Abcam). GAPDH and actin antibodies for western blot analysis were acquired from Santa Cruz Biotechnology (Santa Cruz, CA, USA).

Immunohistochemistry (IHC) and tissue microarray. The pancreatic cancer tissue microarrays were purchased from Xian Ailina Biotechnology Co., Ltd. (Xian Ailina Biotechnology Co., Ltd., China). The expression of Akt was measured by IHC as described (22). Akt staining in human tissues were scored independently by two pathologists, by evaluating a semiquantitative immunoreactivity score (IRS) as described (23). Then, tissues with IRS 0-5 and IRS 6-9 were defined as low and high expression of Akt, respectively.

Short hairpin RNA. The short hairpin RNA for Plk1 (shPlk1) and empty vector $(\mathrm{EV})$ was synthesized with the vector pYr-1.1 (hU6/EGFP/Neo) (Changsha Yingrun Biotechnology Co., Ltd., China). Cell HEK 293 (ATCC, USA) was used to pack recombination adenovirus and the empty vector (EV) was constructed as an experimental control.

Cell proliferation assay. The cell lines of AsPC-1, BxPC-3, and PANC-1 were seeded in 96-well dishes at $1 \times 10^{4}$ cells per well. Cell viability was determined by MTT assays after cells were incubated with different concentrations of LY294002 (Cell Signaling Technology, USA) for $24 \mathrm{~h}$.

Quantitative reverse transcription-PCR ( $q R T-P C R)$ assay. The mRNA level was quantified by qRT-PCR. Primers used for the Akt gene: forward, 5'-TCACCATCACACCACCT GAC-3'; and reverse, 5'-CTCAAATGCACCCGAGAAAT-3'. Primers used for the Plk1 gene: forward, 5'-ACC AGC ACG TCG TAG GAT TC-3'; and reverse 5'-ATA ACT CGG TTT CGG TGC AG-3'. Primers used for the GAPDH gene were 5'-AAC GGA TTT GGT CGT ATT GG-3' (forward) and 5'-GGA TCT CGC TCC TGG AAG AT-3' (reverse) (Invitrogen, USA).

Western blot analysis. Cells were washed in cold PBS twice, then solubilized in RIPA lysis buffer (Vazyme, Nanjing, China). Samples with the same amount of protein were analyzed by western blotting as described (24).

Flow cytometry. Apoptosis was detected by flow cytometry. The cells were incubated with LY294002 for $48 \mathrm{~h}$ or recom- binant adenovirus for 24,48 and $72 \mathrm{~h}$; then washed twice with ice-cold PBS and resuspended in 1x binding buffer (BD Pharmingen, USA) at a concentration of $1 \times 10^{5}$ cells $/ \mathrm{ml}$. Added $5 \mu \mathrm{l}$ of APC Annexin V (BD Pharmingen) and $5 \mu \mathrm{l}$ of 7-AAD (BD Pharmingen). Then, samples were analyzed by flow cytometer (BD FACSCalibur equipped with CellQuest Pro).

Tumor xenograft model. Human pancreatic cancer cells (dissolved in PBS; $1 \times 10^{7} / 120 \mu 1$; BxPC-3) were injected subcutaneously in the right subaxillary of female nude mice (Chinese Academy of Sciences, Shanghai, China). When tumor volume was $80-120 \mathrm{~mm}^{3}, 12$ nude mice were divided into two groups (control group, LY294002 group) randomly. The LY294002 group was injected with LY294002 $(25 \mathrm{mg} / \mathrm{kg} / \mathrm{d}$; dissolved in DMSO) via the abdominal route; and the control group was treated with equal $1 \%$ DMSO via the abdominon. Tumor volume was observed every 2 days and was calculated by the formula: (length $\mathrm{x}$ width $\left.{ }^{2}\right) / 2$. Mice were sacrificed at day 12 and the weight and volume of the tumors were measured. Then the tumor along the maximum transverse incision was cut in half: one half was made into paraffin block after fixation in $4 \%$ neutral formaldehyde and the other half was cryopreserved at $-80^{\circ} \mathrm{C}$. All animals received human care and all experiments were carried out according to the guidelines outlined in the Guide for the Care and Use of Laboratory Animals.

Terminal deoxynucleotidyl transferase dUTP nick end labeling (TUNEL) assay. Paraffin blocks were cut into slices with $4 \mu \mathrm{m}$ thickness. The TUNEL Brighted Apoptosis Detection kit (Vazyme) was used to detect cellular apoptosis in tumor tissues according to the instructions.

Statistical analysis. All statistical analyses were performed using GraphPad Prism 5.0 software (GraphPad Software, Inc., La Jolla, CA, USA). Each experiment was performed three times. All data were expressed as mean \pm SD unless otherwise specified. Data from each group were statistically analyzed using a two-tailed Student's t-test, except immunohistochemical score which was analyzed by Chi-square test. Differences were considered statistically significant at $\mathrm{P}<0.05$. P-values of the statistical significances for differences were set as ${ }^{*} \mathrm{P}<0.05$, ${ }^{* *} \mathrm{P}<0.01$ and ${ }^{* * *} \mathrm{P}<0.001$, as shown in the figures.

\section{Results}

Akt is overexpressed in pancreatic cancer. Immunohistochemistry staining was used to detect the expression of Akt in pancreatic cancer. The staining of pancreatic tissue microarray (including 51 cases of normal pancreas and 91 cases of pancreatic cancer) showed that $27 \%$ of normal tissues had Akt positive staining ( $88 \%$ with low expression, IRS $0-5 ; 12 \%$ with high expression, IRS 6-12), whereas $59 \%$ of tumor tissues had Akt positive staining (71\% with low expression, IRS 0-5; 29\% with high expression, IRS 6-12) (Fig. 1A and B, Table I). The expression of Akt in tumor tissues was significantly higher than it in normal tissues $(\mathrm{P}<0.05)$.

Correlation of Akt levels with clinical characteristics. According to the study of the relationship between the expression level of Akt in pancreatic cancer tissues and the clinical 
A

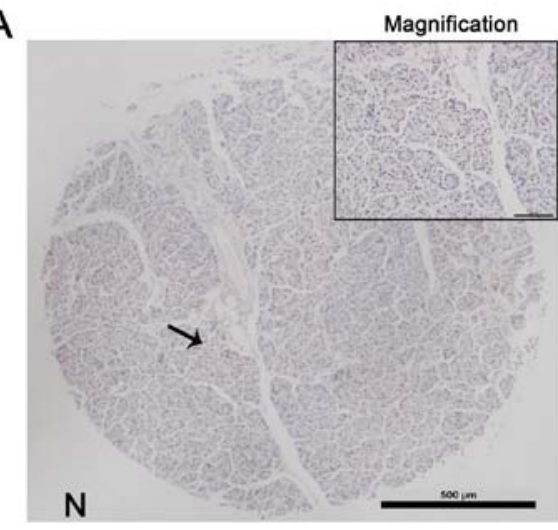

B

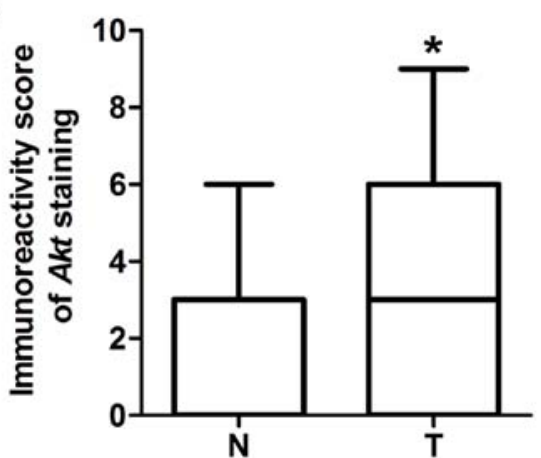

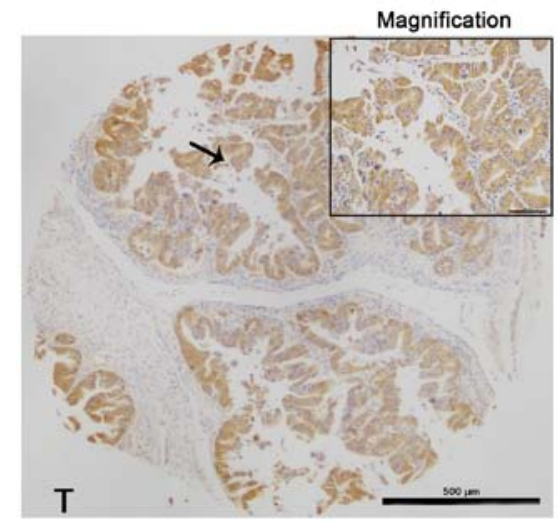

C

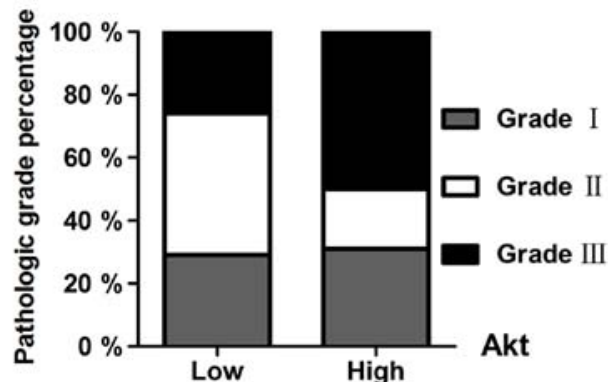

Figure 1. Akt is overexpressed in pancreatic cancer and correlated to tumor pathologic grade. (A) Immunohistochemistery staining of Akt in normal human pancreas and pancreatic cancer. N, normal pancreas tissue; T, tumor tissue. Scale bar, $100 \mu \mathrm{m}$. (B) Immunohistochemical scores showed Akt expression was significantly higher in pancreatic cancer (91 cases) than that in normal pancreas (51 cases) $\left({ }^{*} \mathrm{P}<0.05\right)$. (C) Akt high expression is related to higher pathologic grade.

Table I. Expression of Akt in human pancreas and pancreatic cancer.

\begin{tabular}{lcccc}
\hline & \multicolumn{3}{c}{ Expression of Akt in pancreatic cancer } \\
\cline { 2 - 5 } Group & $\mathrm{n}$ & $\begin{array}{c}\text { Low } \\
\text { expression } \\
(\%)\end{array}$ & $\begin{array}{c}\text { High } \\
\text { expression } \\
(\%)\end{array}$ & P-value \\
\hline Normal tissue & 51 & $45(88)$ & $6(12)$ & $0.021^{\mathrm{a}}$ \\
Pancreatic cancer & 91 & $65(71)$ & $26(29)$ & \\
\hline
\end{tabular}

characteristics of these patients, there was no significantly difference among gender, age or clinical stage. However, Akt expression level was correlated with pathologic grade and there were more cancer tissues with Akt high expression in grade 3 than those in grade 1-2 (grade 1-2 with 79\% low expression and $21 \%$ high expression of Akt; grade 3 with $57 \%$ low expression and $43 \%$ high expression of $\mathrm{Akt}$; $\mathrm{P}<0.05$ ) (Fig. $1 \mathrm{C}$ and Table II).

Inhibition of the PI3K/Akt pathway could reduce cell proliferation and induce apoptosis in pancreatic cancer cells in vitro. Cell proliferation influenced by different concentrations of LY294002 was detected by MTT assay (Fig. 2A). The optimal concentrations of LY294002 for different pancreatic cancer cell lines were $\mathrm{IC} 50_{\mathrm{AsPC}-1}=40 \mu \mathrm{M}, \mathrm{IC} 50_{\mathrm{BxPC}-3}=15 \mu \mathrm{M}$
Table II. The relationship between the expression level of Akt in pancreatic cancer and the clinical characteristics of the patients.

\begin{tabular}{|c|c|c|c|c|}
\hline \multirow[b]{2}{*}{ Characteristics } & \multicolumn{4}{|c|}{ Expression of Akt in pancreatic cancer } \\
\hline & $\mathrm{n}$ & $\begin{array}{c}\text { Low } \\
\text { expression } \\
(\%)\end{array}$ & $\begin{array}{c}\text { High } \\
\text { expression } \\
(\%)\end{array}$ & P-value \\
\hline Gender & & & & 0.842 \\
\hline M & 47 & $34(72)$ & $13(28)$ & \\
\hline $\mathrm{F}$ & 44 & $31(70)$ & $13(30)$ & \\
\hline Age & & & & 0.273 \\
\hline$<60$ & 57 & $43(75)$ & $14(25)$ & \\
\hline$\geq 60$ & 34 & $22(65)$ & $12(35)$ & \\
\hline Pathologic grade & & & & 0.029 \\
\hline $1-2$ & 61 & $48(79)$ & $13(21)$ & \\
\hline 3 & 30 & $17(57)$ & $13(43)$ & \\
\hline Clinical stage & & & & 0.602 \\
\hline I-II & 78 & $57(73)$ & $21(27)$ & \\
\hline III-IV & 13 & $8(62)$ & $5(38)$ & \\
\hline
\end{tabular}

and $\mathrm{IC} 50_{\mathrm{PANC}-1}=35 \mu \mathrm{M}$, respectively. Then qRT-PCR showed LY294002 had no effect on mRNA level of Akt (Fig. 2B). While protein level of $\mathrm{p}$-Akt was downregulated and it suggested that 
A

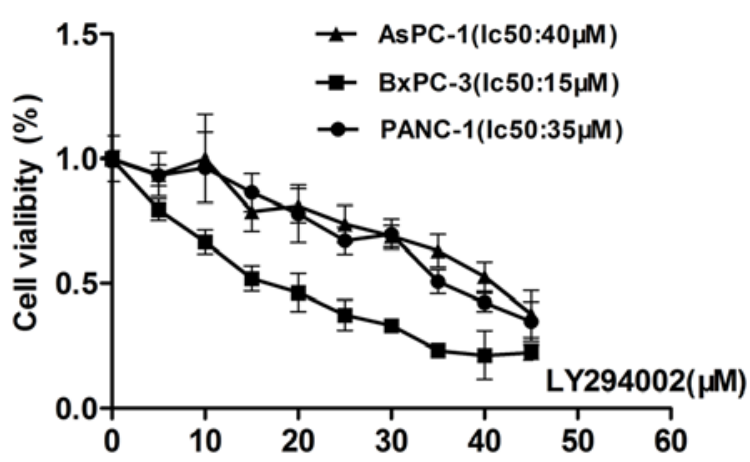

C
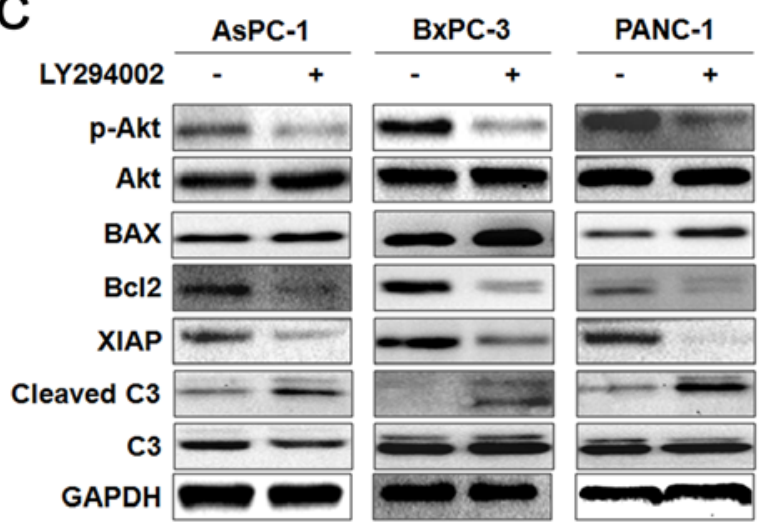

B

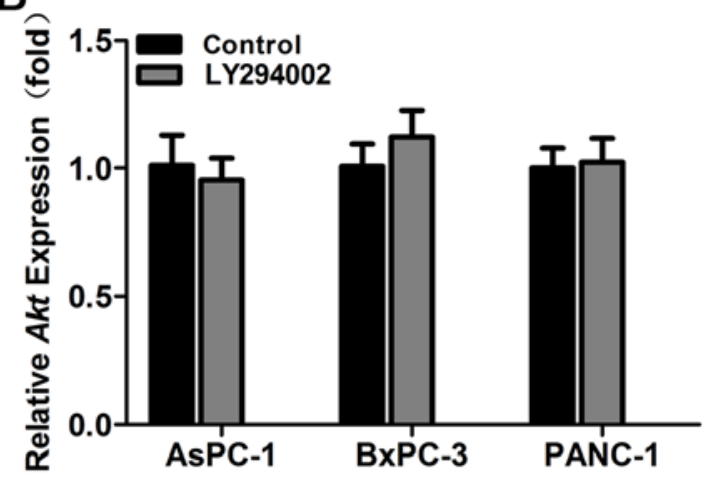

D

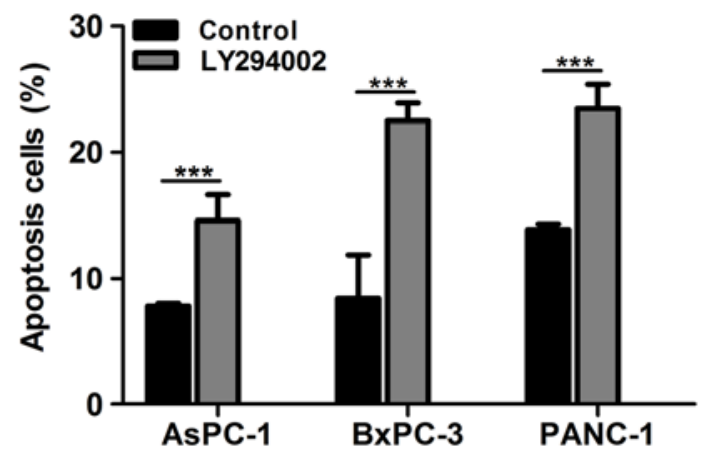

$\mathrm{E}$
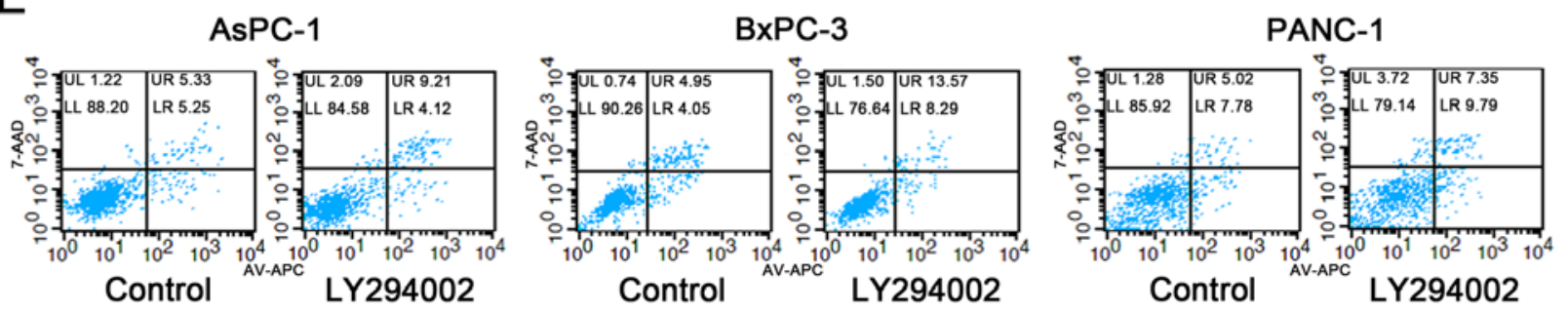

Figure 2. Inhibition of the PI3K/Akt pathway can reduce cell proliferation and induce apoptosis in pancreatic cancer in vitro. (A) The optimal concentration of LY294002 in different pancreatic cancer cell lines was clarified by MTT assay. (B) qRT-PCR showed no significant difference in Akt expression after cells were treated with LY294002 for $24 \mathrm{~h}$. (C) Akt and apoptosis related proteins were detected by western blotting after cells were treated with LY294002 for $48 \mathrm{~h}$. LY294002 could induce apoptosis in pancreatic cancer through downregulating the Bcl-2/Bax ratio, XIAP and activating caspase-3. (D and E) Cell apoptosis was determined by flow cytometry and LY294002 could induce significant apoptosis in pancreatic cancer. Each experiment was performed three times and all data were expressed as mean $\pm \mathrm{SD},{ }^{* * *} \mathrm{P}<0.001$

LY294002 influenced PI3K/Akt pathway through decreasing phosphorylation of Akt (Fig. 2C). As described previously, the PI3K/Akt pathway is an important survival signaling pathway in pancreatic cancer and it is supposed to be related to cell apoptosis in pancreatic cancer. Compared to the control group, using LY294002 to block PI3K/Akt pathway it could induce significant apoptosis $(\mathrm{P}<0.001)$ (Fig. 2D and $\mathrm{E})$. Then we detected the expression level of apoptosis-related proteins such as XIAP, Bcl-2, BAX and caspase-3 by western blotting and found that both caspase-dependent signaling pathway (downregulating XIAP and upregulating cleaved caspase-3) and $\mathrm{Bcl}-2$ family mediated signaling pathway (downregulating Bcl-2 and upregulating BAX) contributed to the apoptosis induced by LY294002 (Fig. 2C). That means PI3K/Akt pathway can control cell survival through several routes and
LY294002 might become an ideal drug to induce cancer cell apoptosis.

Plk1 plays a crucial role in the pancreatic cancer cell apoptosis induced by PI3K/Akt pathway inhibition. Plk1 is essential for cell cycle regulation and our previous study showed Plk1 overexpression is correlated to cell proliferation and chemotherapy resistance in pancreatic cancer (25). As PI3K/Akt pathway is reported to be linked to anti-apoptotic signal transduction and chemoresistance of pancreatic cancer $(26,27)$, the relationship between Plk1 and PI3K/Akt pathway is worthy of study and concern. Then we constructed recombinant adenovirus rAd-Plk1-shRNAs (shPlk1) to further confirm the effect of Plk1 in the process of apoptosis induced by PI3K/Akt pathway inhibition. LY294002 can downregulate Plk1 mRNA 
A

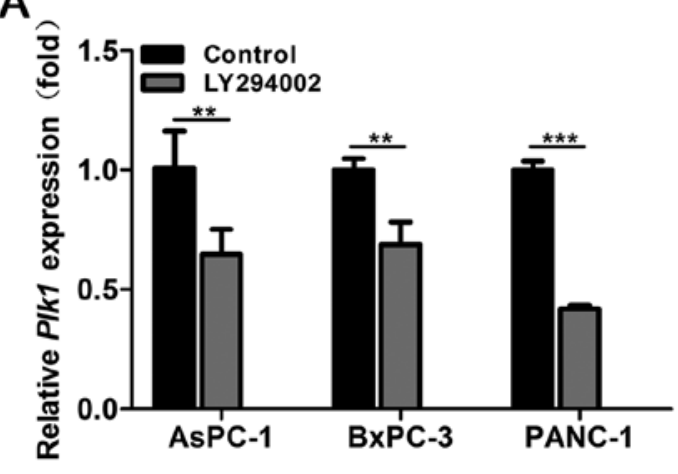

C
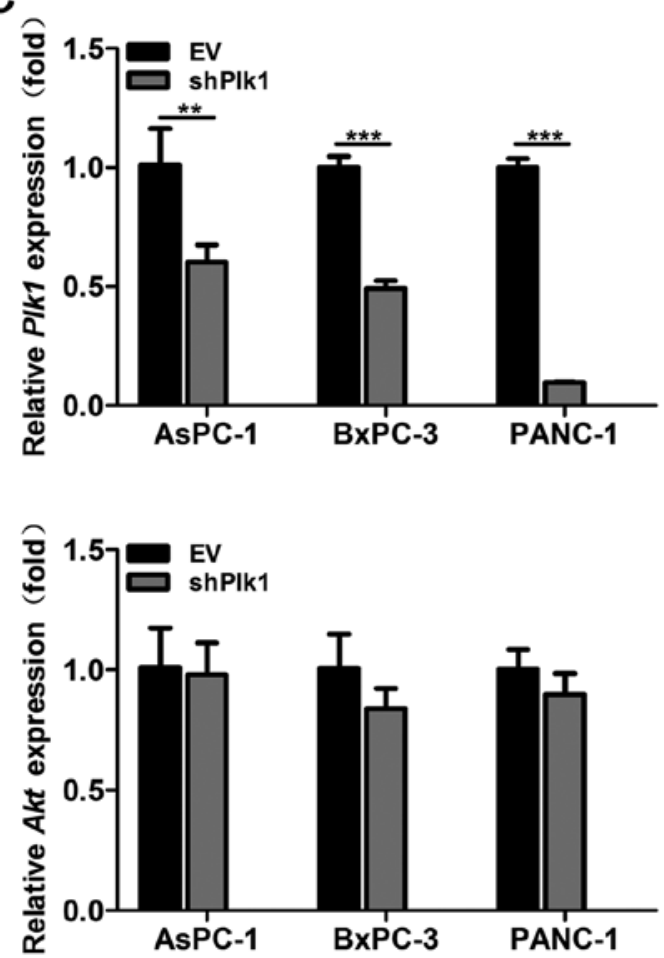

B
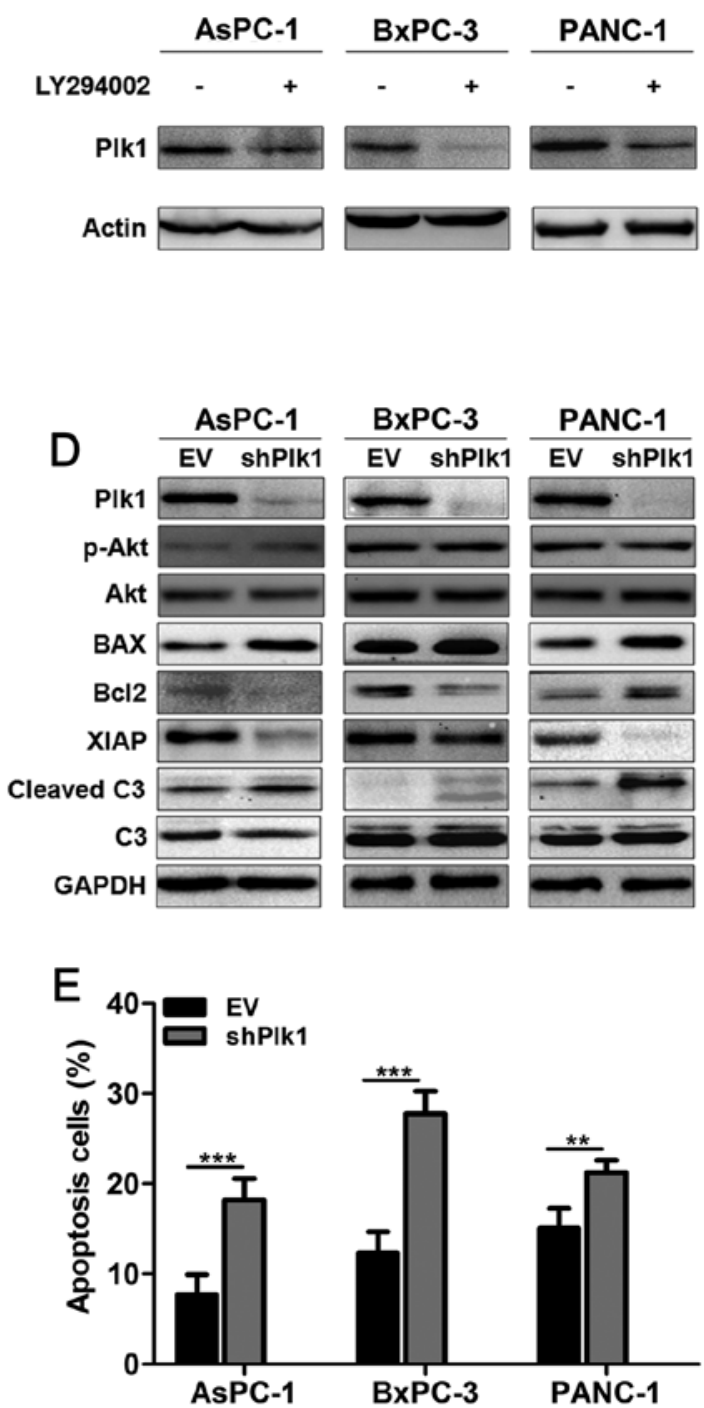

$\mathbf{F}$
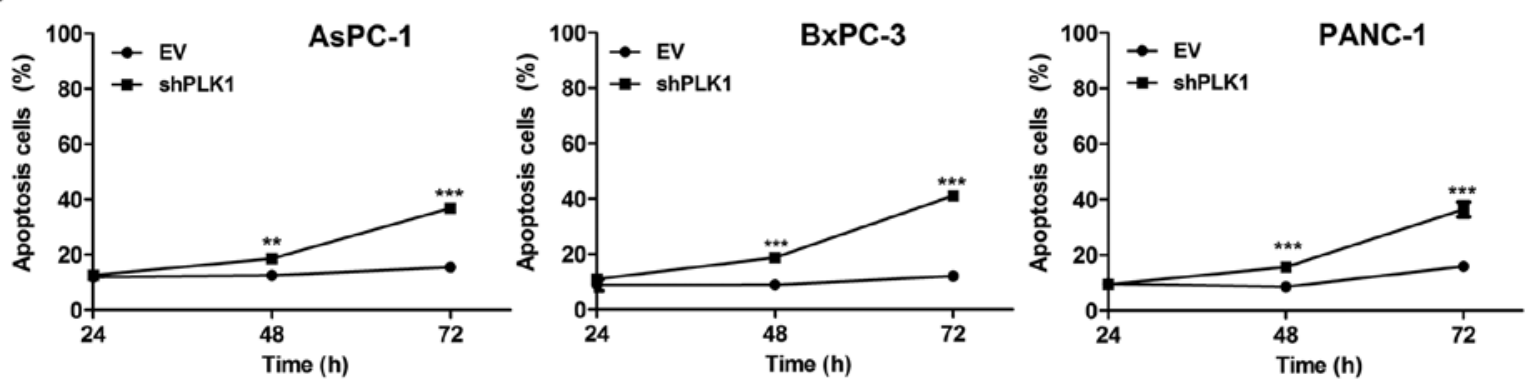

Figure 3. Plk1 plays a crucial role in the pancreatic cancer cell apoptosis induced by PI3K/Akt pathway inhibition. (A and B) qRT-PCR and western blotting showed the Plk1 mRNA and protein levels were decreased after cells were treated with LY294002 for 24 and $48 \mathrm{~h}$ respectively. (C) qRT-PCR showed the Plk1 mRNA level was downregulated after cells were treated with shPlk1 for $24 \mathrm{~h}$ compared to the EV group, while the Akt level showed no significant difference. (D) Plk1, Akt and apoptosis related proteins were detected by western blotting after cells were treated with EV or shPlk1 for $48 \mathrm{~h}$, respectively. The protein level of Plk1 in the shPlk1 group was decreased while the protein level of Akt showed no significant difference, compared to the control group. Plk1 knockdown could induce cell apoptosis in pancreatic cancer cells. (E and F) Cell apoptosis was determined by flow cytometry and downregulating Plk1 could induce significant apoptosis in pancreatic cancer. Each experiment was performed three times and all data were expressed as mean $\pm \mathrm{SD},{ }^{* *} \mathrm{P}<0.01,{ }^{* * * *} \mathrm{P}<0.001$.

level as well as Plk1 protein level $(\mathrm{P}<0.01)$ (Fig. 3A and $\mathrm{B})$ while Plk1 suppression has no influence on the expression of Akt (Fig. 3C and D). Flow cytometry showed Plk1 knockdown could induce significant apoptosis in pancreatic cancer cells as cancer cells infected with shPlk1 for $48 \mathrm{~h}$ had obviously higher apoptosis rate than the EV group $(\mathrm{P}<0.01)$ (Fig. $3 \mathrm{E}$ and $\mathrm{F})$. We also found that Plk1 knockdown induced cancer cell apoptosis through downregulating XIAP, Bcl-2 and upregulating cleaved 
A

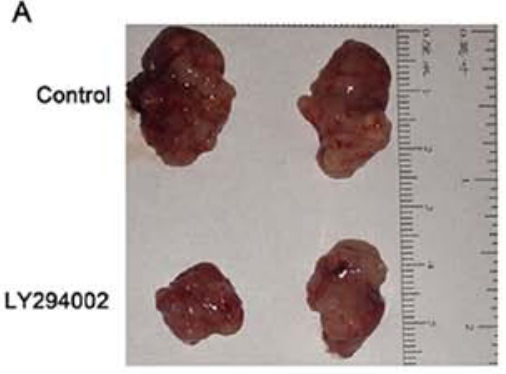

D
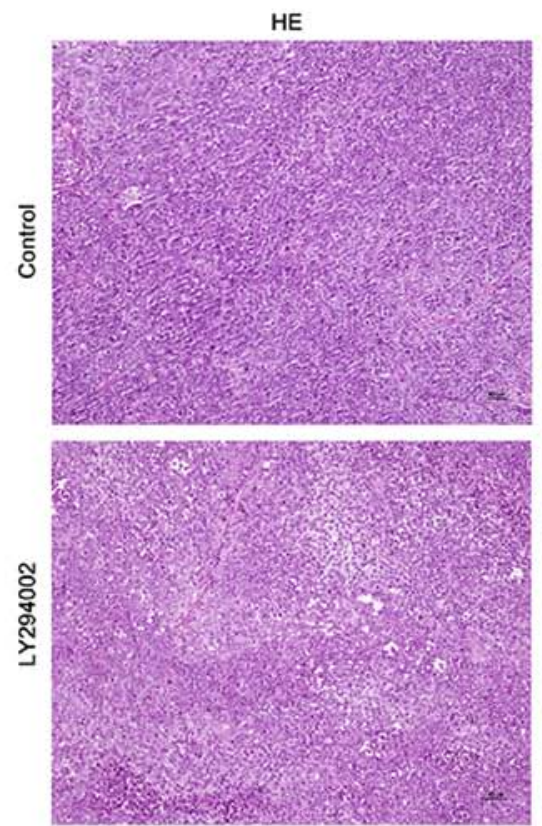

$E$
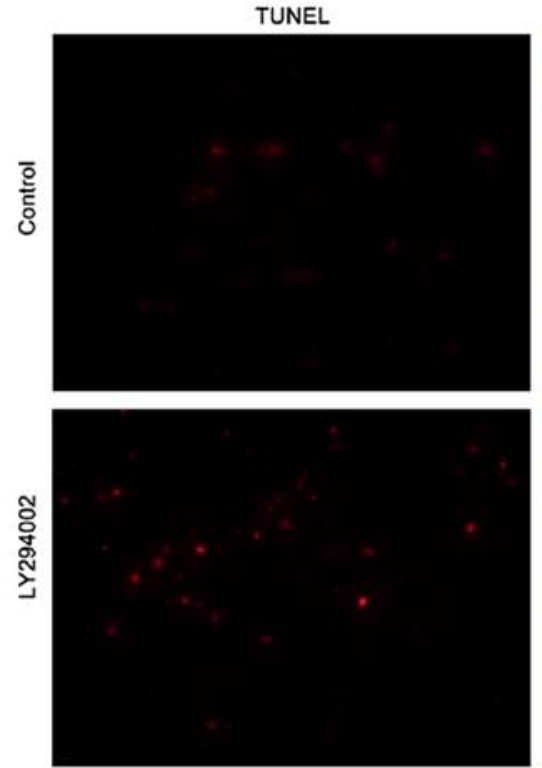

B

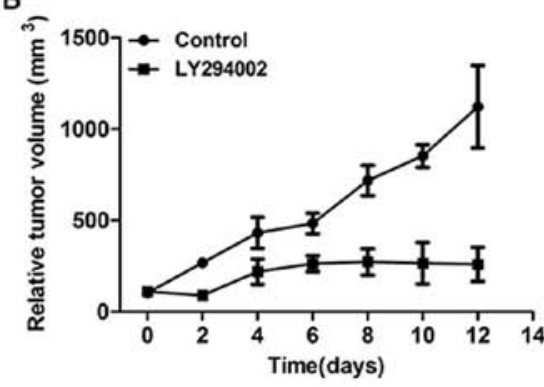

C

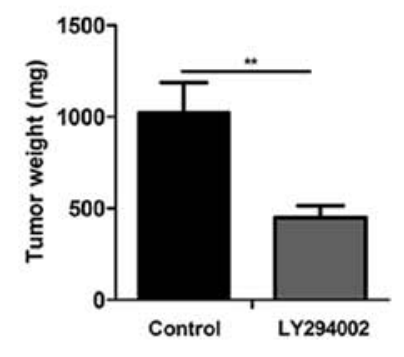

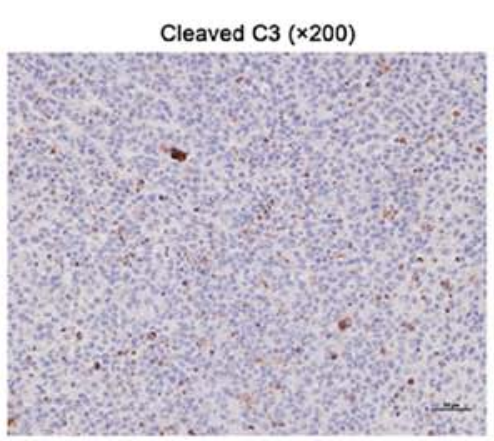
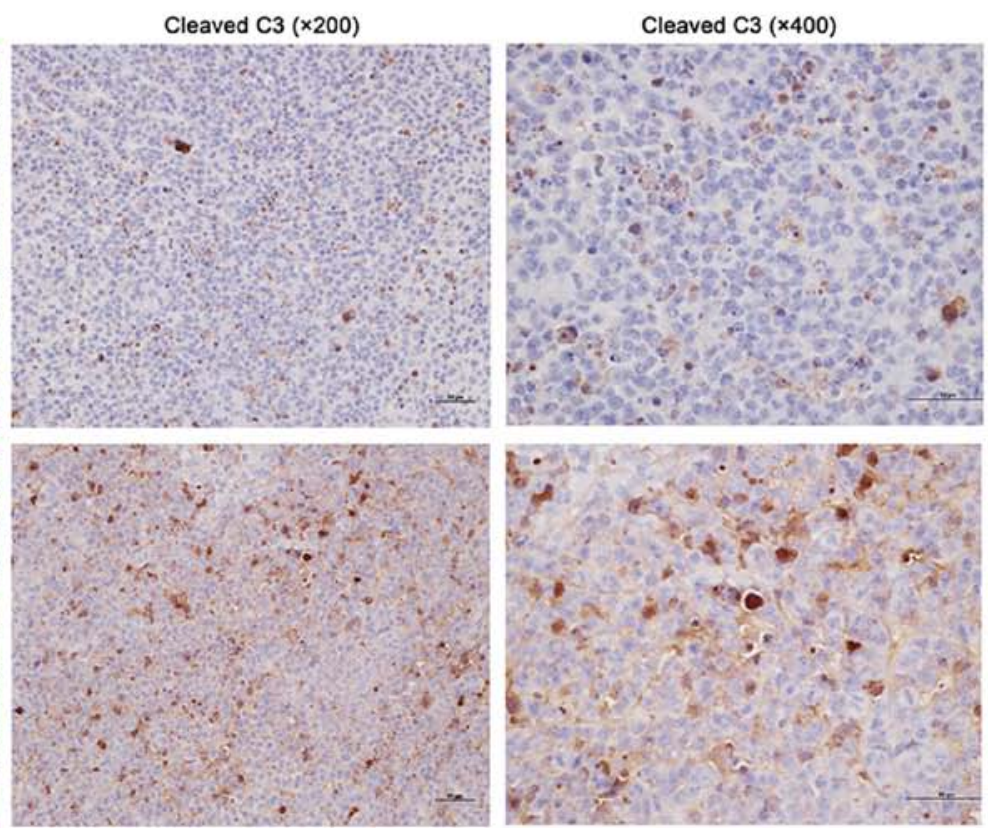

DAPI
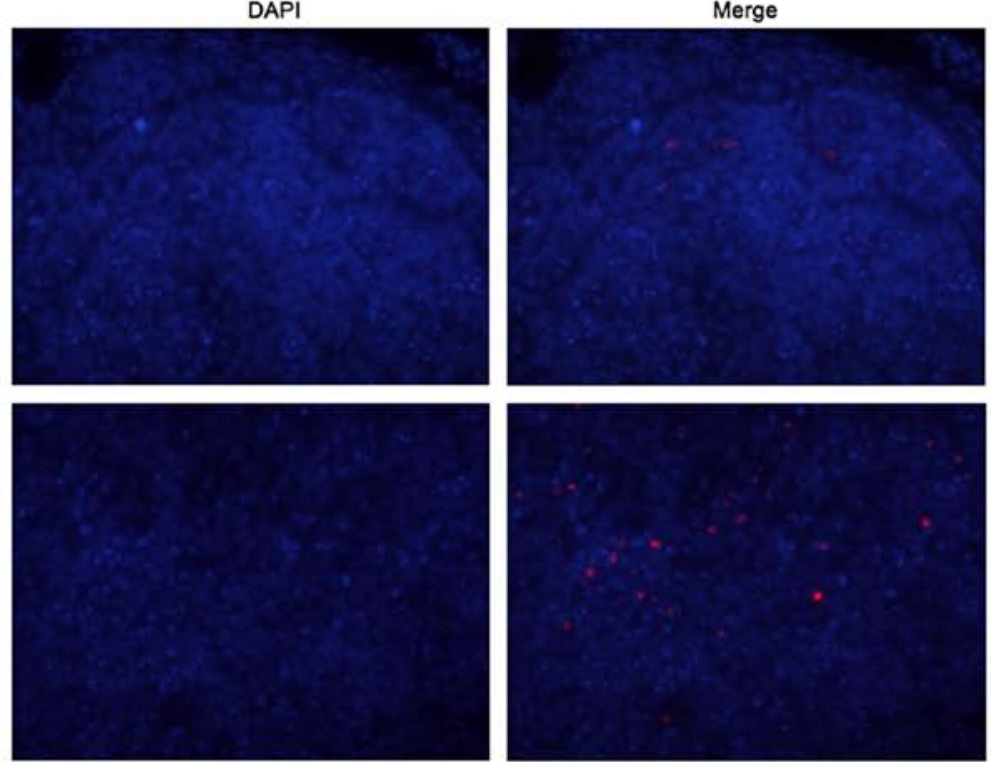

Figure 4. PI3K/Akt pathway inhibition suppresses pancreatic cancer growth and induced apoptosis in vivo. (A-C) LY294002 could diminish the tumor size and weight according to the measurement of the resected tumors $\left({ }^{* *} \mathrm{P}<0.01\right)$. (D) Hematoxylin-eosin staining showed more necrosis and higher expression of cleaved caspase-3 in LY294002 group. (E) TUNEL assay showed higher cell apoptosis rate in the LY294002 group than that in the control group in vivo.

caspase-3 and BAX (Fig. 3D). Thus as a result, we believe that LY294002 could activate apoptosis-related pathway, such as caspase-related or Bcl-2 family-mediated pathway through downregulating Plk1. 
PI3K/Akt pathway inhibition suppressed pancreatic cancer growth and induced apoptosis in vivo. Finally, we investigated the effect of PI3K/Akt pathway inhibition in vivo through a tumor xenograft model. In the BxPC-3 xenograft model, both the tumor volume $\left(1,122 \pm 226\right.$ vs $\left.260 \pm 94 \mathrm{~mm}^{3} ; \mathrm{P}<0.01\right)$ and the weight $(1,025 \pm 161$ vs $449 \pm 65 \mathrm{mg} ; \mathrm{P}<0.01)$ of LY294002 group were significantly less than the control group (Fig. 4A-C). Hematoxylin-eosin staining showed more necrosis and higher expression of cleaved caspase-3 in LY294002 group (Fig. 4D). TUNEL assay revealed LY294002 induced pancreatic cancer cell apoptosis in the tumor xenograft model (Fig. 4E). All the data above indicated that inhibition of PI3K/Akt pathway could suppress pancreatic cancer growth and induced tumor necrosis and cell apoptosis in vivo.

\section{Discussion}

Pancreatic cancer is a malignant tumor with 5-year survival $<5 \%$, despite years of efforts, $\sim 80 \%$ of patients have locally advanced or metastatic disease when they are diagnosed (28).

PI3K/Akt pathway is important in the development and progression of pancreatic cancer and its activation is a common event during this process (29-31). Schlieman et al (10) found activation of Akt existed in half of pancreatic cancer cases, which is consistent with the result of our study. Our study also revealed that the expression level of Akt was closely related to the pathologic grade of pancreatic cancer (Table II). Thus, inhibition of PI3K/Akt pathway could be a potential therapeutic target for the treatment of pancreatic cancer. Kim et al (32) showed Akt inhibition could enhance chemosensitivity of gemcitabine in pancreatic cancer, Bondar et al (33) and our study showed inhibition of PI3K/Akt pathway induces cell apoptosis and reduces cell proliferation in pancreatic cancer, but the mechanism of this process is unclear.

Apoptosis plays an important role in the growth and development of mammals and its deregulation results in many diseases, especially tumorigenesis (34-36). There are two apoptosis pathways: intrinsic pathway and extrinsic pathway. Most apoptosis are induced by the intrinsic pathway which is activated by intracellular signals generated such as caspase signaling pathway when cells are stressed (37). It is reported that XIAP is phosphorylated by Akt at residue serine 87 in vitro and in vivo and this process results in resistance to cisplatin-induced XIAP degradation, caspase-3 activation, and apoptosis (38). Our study showed similar results that XIAP was downregulated and cleaved caspase-3 was upregulated after PI3K/Akt pathway was inhibited by LY294002 in pancreatic cancer. Moreover, we explored whether Bcl-2 family mediated apoptosis is related to PI3K/Akt pathway inhibition and found $\mathrm{Bcl}-2 / \mathrm{BAX}$ ratio was decreased after pancreatic cancer cells were treated with LY294002, indicating that PI3K/Akt pathway inhibition can induce cancer cell apoptosis by activating Bcl-2 family-mediated apoptosis pathway.

As described previously, both PI3K/Akt pathway and Plk1 play an important role in the development, progression and chemoresistance of pancreatic cancer and PI3K/ Akt-dependent phosphorylation of Plk1-Ser99 is required for metaphase-anaphase transition (20,25-27). Our previous study revealed Plk1 knockdown could lead to cell cycle arrest and enhance chemosensitivity to gemcitabine in pancreatic cancer.
Our present study indicated that Plk1 knockdown could induce apoptosis in pancreatic cancer through downregulating XIAP, Bcl-2 and upregulating cleaved caspase- 3 and BAX. At the same time, PI3K inhibitor LY294002 downregulated Plk1 and induce apoptosis. It means that PI3K/Akt pathway inhibition can induce cancer cell apoptosis through activating the caspase pathway and decreasing Bcl-2/BAX ratio via suppression of Plk1 expression.

In conclusion, this study implied that PI3K/Akt pathway inhibition could suppress cell proliferation and lead to cell apoptosis in pancreatic cancer. Apoptosis induced by PI3K/Akt pathway inhibition is correlated with the expression of Plk1 and downregulating Plk1 can activate apoptosis-related pathway, such as caspase-related and Bcl-2 family-mediated pathway. These results indicate that combination therapy, especially targeting to PI3K/Akt pathway might be an achievable access for the treatment of pancreatic cancer.

\section{Acknowledgements}

This study was supported in part by grants from the National Natural Science Foundation of China (nos. 30972910 and 81172269) and Natural Science Foundation of Jiangsu Province, P.R. China (no. 050104313).

\section{References}

1. Siegel RL, Miller KD and Jemal A: Cancer statistics, 2015. CA Cancer J Clin 65: 5-29, 2015.

2. Bilimoria KY, Bentrem DJ, Ko CY, Stewart AK, Winchester DP and Talamonti MS: National failure to operate on early stage pancreatic cancer. Ann Surg 246: 173-180, 2007.

3. Duong HQ, Kim HJ, Kang HJ, Seong YS and Bae I: ZSTK474, a PI3K inhibitor, suppresses proliferation and sensitizes human pancreatic adenocarcinoma cells to gemcitabine. Oncol Rep 27: 182-188, 2012.

4. Yuan TL and Cantley LC: PI3K pathway alterations in cancer: Variations on a theme. Oncogene 27: 5497-5510, 2008.

5. Bellacosa A, Kumar CC, Di Cristofano A and Testa JR: Activation of AKT kinases in cancer: Implications for therapeutic targeting. Adv Cancer Res 94: 29-86, 2005.

6. Michl P and Downward J: Mechanisms of disease: PI3K/ AKT signaling in gastrointestinal cancers. Z Gastroenterol 43: 1133-1139, 2005.

7. Falasca M, Selvaggi F, Buus R, Sulpizio S and Edling CE: Targeting phosphoinositide 3-kinase pathways in pancreatic cancer - from molecular signalling to clinical trials. Anticancer Agents Med Chem 11: 455-463, 2011.

8. Edling CE, Selvaggi F, Buus R, Maffucci T, Di Sebastiano P, Friess H, Innocenti P, Kocher HM and Falasca M: Key role of phosphoinositide 3-kinase class IB in pancreatic cancer. Clin Cancer Res 16: 4928-4937, 2010.

9. Yamamoto S, Tomita Y, Hoshida Y, Morooka T, Nagano H, Dono K, Umeshita K, Sakon M, Ishikawa O, Ohigashi H, et al: Prognostic significance of activated Akt expression in pancreatic ductal adenocarcinoma. Clin Cancer Res 10: 2846-2850, 2004.

10. Schlieman MG, Fahy BN, Ramsamooj R, Beckett L and Bold RJ: Incidence, mechanism and prognostic value of activated AKT in pancreas cancer. Br J Cancer 89: 2110-2115, 2003.

11. Elghazi L, Weiss AJ, Barker DJ, Callaghan J, Staloch L, Sandgren EP, Gannon M, Adsay VN and Bernal-Mizrachi E: Regulation of pancreas plasticity and malignant transformation by Akt signaling. Gastroenterology 136: 1091-1103, 2009.

12. Strebhardt K: Multifaceted polo-like kinases: Drug targets and antitargets for cancer therapy. Nat Rev Drug Discov 9: 643-660, 2010.

13. Holtrich U, Wolf G, Bräuninger A, Karn T, Böhme B, RübsamenWaigmann $\mathrm{H}$ and Strebhardt K: Induction and down-regulation of PLK, a human serine/threonine kinase expressed in proliferating cells and tumors. Proc Natl Acad Sci USA 91: 1736-1740, 1994. 
14. Weichert W, Schmidt M, Jacob J, Gekeler V, Langrehr J, Neuhaus P, Bahra M, Denkert C, Dietel M and Kristiansen G: Overexpression of Polo-like kinase 1 is a common and early event in pancreatic cancer. Pancreatology 5: 259-265, 2005.

15. Song B, Liu XS, Rice SJ, Kuang S, Elzey BD, Konieczny SF, Ratliff TL, Hazbun T, Chiorean EG and Liu X: Plk1 phosphorylation of orc 2 and hbol contributes to gemcitabine resistance in pancreatic cancer. Mol Cancer Ther 12: 58-68, 2013.

16. Lo ACY, Woo TTY, Wong RL and Wong D: Apoptosis and other cell death mechanisms after retinal detachment: Implications for photoreceptor rescue. Ophthalmologica 226 (Suppl 1): 10-17, 2011.

17. Christensen ME, Jansen ES, Sanchez W and Waterhouse NJ: Flow cytometry based assays for the measurement of apoptosisassociated mitochondrial membrane depolarisation and cytochrome c release. Methods 61: 138-145, 2013.

18. Fulda S and Debatin KM: Extrinsic versus intrinsic apoptosis pathways in anticancer chemotherapy. Oncogene 25: 4798-4811, 2006.

19. Fulda S, Galluzzi L and Kroemer G: Targeting mitochondria for cancer therapy. Nat Rev Drug Discov 9: 447-464, 2010.

20. Kasahara K, Goto H, Izawa I, Kiyono T, Watanabe N, Elowe S, Nigg EA and Inagaki M: PI 3-kinase-dependent phosphorylation of Plk1-Ser99 promotes association with 14-3-3 gamma and is required for metaphase-anaphase transition. Nat Commun 4: 1882,2013

21. Chen L, Li Z, Ahmad N and Liu X: Plk1 phosphorylation of IRS2 prevents premature mitotic exit via AKT inactivation. Biochemistry 54: 2473-2480, 2015.

22. Wang S, Wu X, Zhang J, Chen Y, Xu J, Xia X, He S, Qiang F, Li A, Shu Y, et al: CHIP functions as a novel suppressor of tumour angiogenesis with prognostic significance in human gastric cancer. Gut 62: 496-508, 2013

23. Weichert W, Röske A, Gekeler V, Beckers T, Ebert MP, Pross M, Dietel M, Denkert C and Röcken C: Association of patterns of class I histone deacetylase expression with patient prognosis in gastric cancer: A retrospective analysis. Lancet Oncol 9: 139-148, 2008.

24. Jia L, Xing J, Ding Y, Shen Y, Shi X, Ren W, Wan M, Guo J, Zheng S, Liu Y, et al: Hyperuricemia causes pancreatic $\beta$-cell death and dysfunction through $\mathrm{NF}-\kappa \mathrm{B}$ signaling pathway. PLoS One 8: e78284, 2013.

25. Yu C, Zhang X, Sun G, Guo X, Li H, You Y, Jacobs JL, Gardner K, Yuan D, Xu Z, et al: RNA interference-mediated silencing of the polo-like kinase 1 gene enhances chemosensitivity to gemcitabine in pancreatic adenocarcinoma cells. J Cell Mol Med 12A: 2334-2349, 2008.
26. Ng SS, Tsao MS, Nicklee T and Hedley DW: Wortmannin inhibits pkb/akt phosphorylation and promotes gemcitabine antitumor activity in orthotopic human pancreatic cancer xenografts in immunodeficient mice. Clin Cancer Res 7: 3269-3275, 2001.

27. Ng SSW, Tsao MS, Chow S and Hedley DW: Inhibition of phosphatidylinositide 3-kinase enhances gemcitabine-induced apoptosis in human pancreatic cancer cells. Cancer Res 60: $5451-5455,2000$

28. Costello E, Greenhalf W and Neoptolemos JP: New biomarkers and targets in pancreatic cancer and their application to treatment. Nat Rev Gastroenterol Hepatol 9: 435-444, 2012.

29. di Magliano MP and Logsdon CD: Roles for KRAS in pancreatic tumor development and progression. Gastroenterology 144: 1220-1229, 2013.

30. Stephen AG, Esposito D, Bagni RK and McCormick F: Dragging ras back in the ring. Cancer Cell 25: 272-281, 2014.

31. Hofmann I, Weiss A, Elain G, Schwaederle M, Sterker D, Romanet V, Schmelzle T, Lai A, Brachmann SM, Bentires-Alj M, et al: K-RAS mutant pancreatic tumors show higher sensitivity to MEK than to PI3K inhibition in vivo. PloS One 7: e44146, 2012.

32. Kim R, Yamauchi T, Husain K, Sebti S and Malafa M: Triciribine phosphate monohydrate, an AKT inhibitor, enhances gemcitabine activity in pancreatic cancer cells. Anticancer Res 35: 4599-4604, 2015.

33. Bondar VM, Sweeney-Gotsch B, Andreeff M, Mills GB and McConkey DJ: Inhibition of the phosphatidylinositol 3'-kinaseAKT pathway induces apoptosis in pancreatic carcinoma cells in vitro and in vivo. Mol Cancer Ther 1: 989-997, 2002.

34. Lowe SW and Lin AW: Apoptosis in cancer. Carcinogenesis 21: 485-495, 2000.

35. Arlt A, Müerköster SS and Schäfer H: Targeting apoptosis pathways in pancreatic cancer. Cancer Lett 332: 346-358, 2013.

36. Goldar S, Khaniani MS, Derakhshan SM and Baradaran B: Molecular mechanisms of apoptosis and roles in cancer development and treatment. Asian Pac J Cancer Prev 16: 2129-2144, 2015.

37. Ivey R, Desai M, Green K, Sinha-Hikim I, Friedman TC and Sinha-Hikim AP: Additive effects of nicotine and high-fat diet on hepatocellular apoptosis in mice: Involvement of caspase 2 and inducible nitric oxide synthase-mediated intrinsic pathway signaling. Horm Metab Res 46: 568-573, 2014.

38. Dan HC, Sun M, Kaneko S, Feldman RI, Nicosia SV, Wang HG, Tsang BK and Cheng JQ: Akt phosphorylation and stabilization of X-linked inhibitor of apoptosis protein (XIAP). J Biol Chem 279: 5405-5412, 2004 